\title{
New Strategies to Identifying and Empowering Gifted Underachievers
}

\author{
Mrs. Sana Ali \\ Research Scholar, Education, Mewar University, Rajasthan, India \\ Lecture, University of Dammam, K.S.A \\ DR. Mohammed Rafi \\ Head/Professor, Education, Al-Madina College of Education \\ Mahboob Nagar District, Telangana, India
}

\begin{abstract}
Underachievers tend to have underdeveloped sequencing skills \& high spatial abilities. Early researchers (Raph, Goldberg, and Passow, 1966) and some recent authors (Davis and Rimm, 1989) have defined underachievement in terms of a discrepancy between a child's school performance and some ability index such as an IQ score. Underachievement is seen as a problem of attitude or work habits. However, neither habits nor attitude can be modified as directly as behaviors. Thus, referring to "underachieving behaviors" pinpoints those aspects of children's lives which they are most able to alter. An underachiever is a person and especially a student who fails to achieve his or her potentialor does not do as well as expected. Whitmore (1989) identified three broad causes for underachievement in gifted children. 1. Lack of motivation to apply themselves in school 2.Environments that do not nurture their gifts and may even discourage high achievement 3.Disabilities or other learning deficits that mask their giftedness. Gifted underachievers are defined as those students who have a large difference between potential and performance: that is, their gifts are not effectively developed into talents.
\end{abstract}

Keywords: underachievers, underachievement, motivation, underachieving behavior

\section{INTRODUCTION}

The Unique group of individuals are yet to get proper attention in our educational system. They represent a global problem "Academic Under achievement". It is a complex phenomenon which affects individuals in terms of continual lack of success in academic performance, the reasons being complex and elusive often lacking proper attention. Gifted Underachievers do not differ from the gifted achievers in mental capacity, powers of reasoning and abstraction, information processing skills and creativity but they reveal a lack of self-confidence, the inability to perceive, lack of sense of purpose or drive and a presence of feelings of inferiority. This group of students having superior ability differ from the gifted high achievers on certain non-intellective variables were ascertained by term and through the study on the gifted. (1959) Individual differences in performance among the bright and the gifted are quite apparent. There is a large number of individuals of very high intelligence who do not perform at the required level to indicate that general intelligence alone doesn't ensure performance but goes side by side with the ability and environment. The problem of underachiever in individuals among the brilliant is of the social concern as well as of the individual welfare and happiness. Considerable attention has been paid to the gifted students, particularly in higher education who do not perform well or achieve results quite below their ability and standard expected of them. Concern about underachievers reflects the concern about the waste of human potential which any developing country needs to avoid. Researchers have called for deeper examination of underachievement among gifted students, particularly through qualitative studies that give deeper insights into the confounding reasons that stimulate this behavior (McCoach and Siegle, 2003; Schultz, 2002b).

\section{WHO ARE UNDERACHIEVERS?}

Lewis (1941) called those students underachievers whose educational ages are one year or more, lower than their mental ages. Gowan (1957 chose gifted children (IQ-130 and above) as underachievers when they fall in the middle third in scholastic achievement in the grades and severe 
underachievers when they fall in the lowest third. Holmes and Finley (1997) described underachievement in terms of grade placement deviation (GPD) as: $\mathrm{GPD}=\mathrm{AGP}-\mathrm{CaCp}+\mathrm{R}$, Where $\mathrm{AGP}=$ Actual Grade Placement, $\mathrm{CaCp}=$ Grade placement expected chronological age. $\mathrm{GPD}=\mathrm{Grade}$ placement Deviation. K=Constant of 0.5 intended to give all values positive sign. Gallanghar (1979) defined underachieving gifted students as those who exhibit a gap between achievement test scores and intelligence test scores. Gowan(1975) summarized the studies comparing gifted underachievers and said that following factors are related to the underachievers. According to L'abate and Curtis (1975) underachievement represents a lower rate of learning than would be otherwise predicted by the level of intellectual functioning. The gifted underachievers tend to be self-sufficient and unsociable towards peers, identifies little with his parents and has few surrogate parent models among teachers because they usually tend to be over achievers.

\subsection{Underachievers may be Classified into two Main Groups}

The first group includes those who are withdrawn, passive individuals who never reach their potential. The second group includes hyperactive and aggressive students who disrupt the class and annoy the lecturers. The concern is about both the groups because the first ones suffer more from negative selfconcept and lack of motivation, whereas the second group suffers from antagonist attitude towards authority as either their needs are not fulfilled or they are bored with the stereotype teaching and curriculum .Their special talents are never called for.

\subsection{Types of Unde rachie vers}

A common misconception is that students who underachieve are lazy, unmotivated, and without goals. While it is true that these individuals are not achieving their full potential because they procrastinate, skip school, and sometimes lie and make outrageous excuses, they do have goals and they are motivated. The difficulty is that their goals are directed towards avoiding achievement and success, rather than attaining it (Mandel, Marcus, \& Dean, 1995). Mandel and colleagues have described six different underachievers.

\subsubsection{Anxious Underachievers}

These students underachieve due to anxiety and tension about performing well. They want to achieve, but they become so overwhelmed with starting their assignment or studying for their test that they end up procrastinating to avoid the uncomfortable feelings. Anxious underachievers constantly worry about being competent, they are perfectionists, and they often waste time worrying about minor details to the point that the task or assignment will not be complete.

\subsubsection{The Identity-Search Underachiever}

These individuals spend so much time trying to figure out who they are and what they stand for that they avoid their own work and goals. These students are intensely concerned about social issues and about experimenting with different styles of dress and different groups of friends to see where they fit in rather than determining what they really want and developing a plan to achieve this.

\subsubsection{The Wheeler-Dealer Underachiever}

These students are impulsive, they live for the moment and they want instant gratification. They will cheat or copy assignments to avoid doing their own work and to avoid the imminent threat of failure because they are not prepared. They will lie, regularly skip school, and will manipulate others to get what they want. Their goals include beating the system and undermining authority.

\subsubsection{The Sad or Depressed Underachiever}

These individuals are low in self - esteem and experience feelings of sadness and Depression which prevent them from achieving. These students lack the energy to concentrate on school work, and they are too fatigued to motivate themselves to achieve.

\subsubsection{The Defiant Underachiever}

These individuals underachieve as an act of rebellion against authority. They are hostile, angry, defiant, and they blame others for their own mistakes and underachievement.

\subsubsection{Coasters}

These are the most common types of underachievers and are described as unmotivated and easygoing. These individuals are easily identified. By their extreme procrastination both at home and at school, and they coast through schoolwork and activities without concern that they have failed or done 
poorly. Coasters give up on challenging tasks or assignments, they have a multitude of excuses for their lack of achievement, and they do not respond positively to rewards or punishments for their coasting behavior. They are able to focus and achieve when they want to (usually in extracurricular or fun activities), and they are not likely to actually fail a subject because they coast by with averages around 50 and $60 \%$.

\subsection{Underachie vement}

Rimm's Trifocal Model $(1986,2001)$ is one of the most comprehensive approaches to underachievement. The model operates on the philosophy that underachievement is learned, and therefore achievement can also be learned. Rimm examines the three major influences on a child's life - home, school, and peer culture - and seeks to understand how these areas contribute to the child's underachievement. Rimm's analysis of the defense mechanisms an underachiever uses to establish "dependent or dominant rituals" (2001, p. 353) provides keen insight into the subtle dynamics between a child and the adults in his life that reinforce a pattern of nonproductive behaviors. Various researchers have quantified underachievement:

Underachievement can be defined as a discrepancy between the child's school performance and some index of his or her actual ability. Ability may be measured by test scores or even by observing the child at home or at school. (Rimm)

Underachieving students have a gap between achievement test scores and intelligence test scores or between academic grades and intelligence test scores. (Gallagher)

A child achieving significantly below the level statistically predicted by his/her IQ. (Newman)

One whose achievement score is lower than his/her ability score. (Kowitz)

When a child with a high IQ has low grades in school. (Ziv)

\subsubsection{Reasons for Underachievement}

Lack of interest in school.

Indifference to marks.

Inferiority feelings.

Factors in the back ground such as inferior home conditions.

Parental negligence.

Lapses in the curriculum design which do not appeal to the intellectual level of thegifted students.

Lack of clear vision and definiteness of an occupational choice.

Weak ego control.

Withdrawal and self -sufficiency.

Poor use of time and money.

Neurotic tendencies.

Authoritarianism in the parental home.

Dominant, autocratic, or laissez-faire parent.

Lack of maturity.

No goals or impossible demands by the parents.

Disinterestedness in other people.

Lack of dominance, persuasiveness and self-confidence.

Apathetic and having withdrawn attitude of life.

2.3.2. Can be said that gifted underachievers

See themselves as inadequate persons.

Have lower aspirations than the overachievers.

Dislike schools.

Avoid learning from books.

Have lower popularity and leadership status.

May come from home of low socioeconomic status or from homes which lack proper emotional climate. 
Do not have clearly defined vocational goals.

Sometimes have adjustment problems.

\subsection{3..Solutions to Underachievement}

Examine the Problem Individually. Underachievement covers a broad spectrum of situations from a minor school problem with a fairly obvious cause to a more entrenched long-term pattern. Since underachievement is such a varied and complex phenomenon, each case must be examined individually - with no preconceptions. As Hansford (2001, p. 316) observes: "Underachievement is very specific to the individual child; intervention and remediation of underachievement must be individually developed and implemented."

Createa Teacher-Parent Collaboration. Teachers and parents need to work together and pool their information and experience regarding the child. Most interventions in the literature involve parentteacher collaborations (e.g., Rimm, 1986, 2001), where they can coordinate their efforts and help the child progress more effectively. Some of the questions teachers and parents can explore together are: In what areas has the child shown exceptional ability? What are the child's preferred learning styles? What insights do parents and teachers have about the child's strengths and problem areas? What does the child say about self-needs, interests, and school experiences, and how is this information to be interpreted? This kind of joint exploration yields useful insight into the nature of the child's abilities and the root of the problem.

Stay focused on the Child's Gifts. When examining a child's underachievement, always begin by focusing on strengths; a deficiency approach encourages the child to focus on weaknesses even more than before. At each point the investigation needs to find the most effective ways to involve the child in the pursuit and exploration of personal talents and interests. This builds the confidence and strength the child needs to manage problem areas.

Create an Individual Plan for the Child. The plan designed for the child has to emerge from the nature of individual gifts and the root causes of the underachievement. An underachieving Native American child, for example, who suffers from low skill development due to poverty, inadequate schooling, and low self-esteem needs an individualized program that will provide mentoring in the development of personal gifts, open-ended projects that allow free exploration and divergent thinking, and also special intervention to strengthen skills. (Scruggs \& Cohn, 1983).

\subsection{Achievement and Motivation}

a. Poor or little motivation leads to underachievement. b. An effective achievement at a good or moderate motivation. c. A serious negative or protest underachievement again for excessive motivation which may be due to too much pressure for parents, extrinsic drive or aggressive achievement motivation. Motivational factors play a significant role for gifted underachievers. (McCoach and Siegle, 2003; Seeley, 2004). As a result, teachers of gifted underachievers must first identify what motivates their students as well as infuse affective support into the classroom routine in order to attempt closure of the gap between potential and performance (Landis and Reschly, 2013; Seeley, 2004). With signs of self-doubt and lack of engagement in the day-to-day curriculum, both common behaviors for gifted underachievers (Hoover-Shultz, 2005; Landis and Reschly, 2013). As discussed by Morisano and Shore (2010), establishment of a conscious goal greatly influences the level of effort a person places on achievement of the goal as well as the persistence, they are willing to display in overcoming obstacles that may arise along the way. What motivates the students is, academic success and, once intensified through personalized engagement and elevated expectations, they will be easily able to overcome their period of underachievement and eventually become a shining star not only in my classroom, but across all of their other academic areas as well. Wellisch and Brown (2012) explain that problems with peers may be alleviated by the teacher acknowledging and celebrating the underachiever's giftedness, as discussed by Schultz (2002a), we must work with students rather than on students. None of the outcomes described in this study would have been possible if had not worked with students in establishing their goals, examining their motivation, and acting as a conduit toward their success. By setting high expectations, fueling motivation and taking into consideration the cultural differences between ourselves and our students, we can make the classroom a more enjoyable and empowering place for everyone, including gifted underachievers; moreover, just as gifted programs should not be one-size-fits-all, neither should our approach to negotiating gifted underachievement (OlszewskiKubilius, 2003). 
2.4.1. Suggestions for motivating students

*Treat the topic with enthusiasm to spark interest.

*Encourage students to think about their performance and how it affects their future goals.

*Help them recognize their accomplishments and growth by charting progress.

*Videotape students as they are engaged in various activities and periodically review the recordings.

*Use specific rather than general compliments.

2.4.2. The role of the teacher is crucial to the success of this approach. Teachers are most effective in reversing the underachievement pattern

- take time to get to know the student before initiating an investigation;

- use their time with students to facilitate the process rather than counsel them regarding their underachievement;

- see their role as a facilitator of the process - for example, by arranging frequent student/teacher conferences, providing resources, allocating school time for students to complete the project, and making suggestions when students seem to be at a standstill;

- understand that students need to act like practicing professionals and share their products with realworld audiences;

- recognize the dynamic nature of the underachievement problem by observing students, reflecting on their behaviors as they work on their projects, and identifying strategies to help students overcome problems;

- Consistently demonstrate patience and believe in the student!

2.4.3. Parentscan help their children find school meaningful in the following ways:

- By modeling their own curiosity about the world around them. However, parents must demonstrate how curiosity is transformed into action. For example, a question about the number of moons orbiting Saturn might lead to looking up the answer on the Internet or in an encyclopedia.

- By nurturing their children's curiosity and love of learning through opportunities outside school that help them explore their interests.

- By letting their children know that they value school and showing them how their school experiences are important now and will prove useful in the future.

- By monitoring their children's homework, which again sends the message that parents value what their children do in school.

- By sharing their children's interests with the school and working with the school and their children to tie these interests to school projects.

2.5. Whitmore (1980) describes three types of strategies that she found effective in working with underachieving behaviors in students:

\subsubsection{Supportive Strategies}

Classroom techniques and designs that allow students to feel they are part of a "family," versus a "factory," include methods such as holding class meetings to discuss student concerns; designing curriculum activities based on the needs and interests of the children; and allowing students to bypass assignments on subjects in which they have previously shown competency.

\subsubsection{Intrinsic Strategies}

These strategies incorporate the idea that students' self-concepts as learners are tied closely to their desire to achieve academically (Purkey and Novak, 1984). Thus, a classroom that invites positive attitudes is likely to encourage achievement. In classrooms of this type, teachers encourage attempts, not just successes; they value student input in creating classroom rules and responsibilities; and they allow students to evaluate their own work before receiving a grade from the teacher.

\subsubsection{Remedial Strategies}

Teachers who are effective in reversing underachieving behaviors recognize that students are not perfect - that each child has specific strengths and weaknesses as well as social, emotional and 
intellectual needs. With remedial strategies, students are given chances to excel in their areas of strength and interest while opportunities are provided in specific areas of learning deficiencies. This remediation is done in a "safe environment in which mistakes are considered a part of learning for everyone, including the teacher.

\section{CONClusion}

The findings emerging from this study support the claim that underachievement is a phenomenon that could be extinguished through paedocentric instruction methods that put the student and his or her needs at the Centre of the learning process, and not as is customary today in most of the education systems around the world. The traditional -frontal teaching method common today does not allow underachieving students to exploit their full potential or to advance from the place in which they have been 'bogged down' for many years. A curriculum that combines teaching with alternative assessment tools could change significantly all the aspects concerned with underachieving students and their involvement and success in the learning processes. Programs could help increase the interest and the significance of learning among the students and develop a model of productive cooperation between teachers and students. The study findings could be seen as directing the reader towards deeper understanding of the underachieving students, as a model for imitation and as an application tool to be used by the education system to extinguish this phenomenon. Similarly, in the teaching model that combines formative assessment, each student is encouraged and nurtured to reach the maximum of his abilities. Parents and teachers can reverse underachievement through different strategies. We want to conclude that this paper will be useful to understand the concepts like underachievers, underachievement, motivating strategies to improve underachievement.

\section{REFERENCES}

Colangelo, N., Kerr, B. A., Christensen, P., \& Maxey, J. (1993).A comparison of gifted underachievers and gifted high achievers. Gifted Child Quarterly, 37, 155-160.

Davis, G. A., \&Rimm, S. B. (1989).Education of the gifted and talented (2nd ed.). Englewood Cliffs, NJ: Prentice Hall.

Dowdall, C. B., \&Colangelo, $N$. (1982), Underachieving gifted students: Review and implications. Gifted Child Quarterly, 26, 179-184.

Fehrenbach, C. R. (1993). Underachieving gifted students: Intervention programs that work. Roeper Review, 16(2), 88-90.

Mandel, H. P., \& Marcus, S, I, (1988). The psychology of underachievement: Differential diagnosis and differential treatment. New York: Wiley.

Rimm, S. (1987).Creative underachievers: Marching to the beat of a different drummer. Gifted Child Today, 10(1), 2-6.

Butler-Por, N. (1993). Underachieving gifted students. In K. A. Heller, F. J. Monks, \& A. H. Passow (Eds.) International handbook of research and development of giftedness and talent (pp. 649668). Oxford: Pergamon.

Clasen, D. R, \&Clasen, R. E. (1995). Underachievement of highly able students and the peer society.Gifted and Talented International, 10 (2), 67-75.

Colangelo, N., Kerr, B., Christensen, P., \& Maxey, J. (1993). A comparison of gifted underachievers and gifted high achievers.Gifted Child Quarterly, 37, 155-160.

Dai, D. Y, Moon, S. M., \&Feldhusen, J. F. (1998). Achievement motivation and gifted students: A social cognitive perspective. Educational Psychologist, 33, 45-63.

Delisle, J. (1982).Learning to underachieve.Roeper Review, 4, 16-18.

Pirozzo, R. (1982). Gifted underachievers.Roeper Review, 4, 18-21.

Richert, E. S. (1991).Patterns of underachievement among gifted students. In J. H. Borland (Series Ed.) \& M. Bireley\& J. Genshaft (Vol. Eds.), Understanding the gifted adolescent, (pp. 139-162). New York: Teachers College Press.

Rimm, S. (1997a). An underachievement epidemic. Educational Leadership, 54 (7), 18-22.

Rimm, S. (1997b). Underachievement syndrome: A national epidemic. In N. Colangelo\& G. A. Davis (Eds.), Handbook of Gifted Education (2nd ed., pp. 416-435). Boston: Allyn and Bacon. 